\title{
Groundwater Flow in a Sandy Tidal Beach 1. One-Dimensional Finite Element Analysis
}

\author{
W. Harrison \\ C. S. Fang \\ S. N. Wang
}

Follow this and additional works at: https://scholarworks.wm.edu/vimsarticles

Part of the Oceanography Commons 


\title{
Groundwater Flow in a Sandy Tidal Beach 1. One-Dimensional Finite Element Analysis
}

\author{
W. HARRISON \\ Erindale College, University of Toronto, Clarkson, Ontario, Canada
}

C. S. FANG AND S. N. WANG

Virginia Institute of Marine Science, Gloucester Point, Virginia $2306 \%$

\begin{abstract}
A 31-day time series of observations of beach water table and tidal fluctuations was obtained from 13 wells along a profile perpendicular to the shoreline at Virginia Beach, Virginia. Finite element techniques were applied to solve the one-dimensional, unsteady state, nonlinear equation for groundwater movement. For the finite element analysis, the semi-infinite mass (unconfined aquifer) had to be replaced by a finite mass. The boundary conditions were found from the field data by directly solving the flow equation with a finite difference technique. The finite element method, using the variational principle, provided a reasonable solution and afforded economy in computer time. Field data were compared with the corresponding finite element solution. The results indicate the general accuracy of the methodology.
\end{abstract}

Several workers [e.g., Grant, 1948; Emery and Foster, 1948; Duncan, 1964] have shown in a qualitative way the importance of the slope of the beach water table and its elevation above tide level to the stability of sandy foreshore slopes. The goal of this work was to document carefully the fluctuations in a beach water table and then develop models of the fluctuations for application to the foreshore stability problem. The present study was directed toward determining the feasibility of a one-dimensional model by using finite element techniques.

A 31-day time series of observations of the variables listed in Table 1 was obtained to document pertinent interactions in the beach-oceangroundwater system. Thirteen wells for monitoring the water table and 26 pipe stations for monitoring changes in beach elevation were positioned along an 83-meter transect oriented perpendicular to the shoreline and extending from the edge of the foredune to the low waterline (Figure 1). Four multitube probes were installed for extracting small amounts of groundwater for tests of salinity and to facilitate dye tests of flow characteristics (Figure 1). The wells consisted of (1) a no. 18 slotted PVC (poly-vinyl-chloride) pipe, $102 \mathrm{~mm}$ in diameter, jetted into the beach to a depth of 3.5 meters and (2) a 32-mm OD steel pipe jetted to a depth of 5 meters and touching the PVC pipe. A float pulley system mounted on the pipes drove a potentiometer that provided a dc output voltage that corresponded linearly to the instantaneous water level. Water table elevations were recorded at the site on computercompatible magnetic tape (after A/D (analogto-digital) conversion). Details for this and the other measurement systems, as well as the complete time series of measurements for the variables in Table 1, appear in Harrison and Fausak [1970].

The gently sloping, quartz sand beach that was studied (Figure 1) has a representative porosity of about $34 \%$ (the median grain diameter of pit samples was $0.37-0.59 \mathrm{~mm}$ ). At Cape Henry, the mean range of the astronomical tide is about 0.85 meter and the spring range is 1.1 meters; the tide is semidiurnal with a slight diurnal inequality.

Low, long-period swells characterized the first 10 days of the 30 -day study period. They were followed by 3 days of high, short-period waves that, combined with a storm surge, resulted in flooding of the backshore (Figure 1) for two 
TABLE 1. Measured and Derived Variables for the Beach-Ocean-Groundwater System at Fort Story, Virginia Beach, Virginia, August 10-September 9, 1969

\begin{tabular}{|c|c|c|c|}
\hline Variable & Sampling Frequency & Value Range & Accuracy Estimate \\
\hline $\begin{array}{l}\text { Elevation of beach surface } E_{b} \text {, } \\
\text { meters msl }\end{array}$ & $\begin{array}{l}\text { High, low, and midtide } \\
\text { levels }\end{array}$ & $-0.940-3.693$ & $\begin{array}{l} \pm 0.005 \text { (above water) } \\
\pm 0.020 \text { (below water) }\end{array}$ \\
\hline $\begin{array}{l}\text { Elevation of tidal plane } E_{t}, \\
\text { meters msl }\end{array}$ & Continuous & $-0.55-1.27$ & \pm 0.05 \\
\hline $\begin{array}{l}\text { Elevation of water table } E_{w} \text {, } \\
\text { meters msl }\end{array}$ & $\begin{array}{l}\text { Every } 10 \text { or every } 15 \\
\text { minutes }\end{array}$ & $0.291-1.999$ & \pm 0.003 \\
\hline $\begin{array}{l}\text { Mean height of } 50 \text { successive } \\
\text { breaking waves }\left\langle H_{b}\right\rangle \\
\text { meters msl }\end{array}$ & $\begin{array}{l}\text { High, low, and midtide } \\
\text { levels }\end{array}$ & $0.19-1.30$ & \pm 0.10 \\
\hline $\begin{array}{l}\text { Slope of the foreshore } m \text {, } \\
\text { degrees }\end{array}$ & $\begin{array}{l}\text { Derived (high, low, } \\
\text { and midtide levels) }\end{array}$ & $4.0-11.0$ & \pm 0.5 \\
\hline $\begin{array}{l}\text { Barometric pressure } p \text {, inches } \\
\text { of mercury }\end{array}$ & Continuous & $29.550-30.285$ & \pm 0.005 \\
\hline Rainfall $r, \mathrm{~cm}$ & Hourly during storms & Trace to 2.22 & \pm 0.1 \\
\hline Position of swash limit $s$ & $\begin{array}{l}\text { Hourly and at high, } \\
\text { low, and midtide levels }\end{array}$ & Stations G-Z & \pm 0.25 meter \\
\hline $\begin{array}{l}\text { Mean period of } 50 \text { successive } \\
\text { breaking waves }\left\langle T_{b}\right\rangle \text {, seconds }\end{array}$ & $\begin{array}{l}\text { High, low, and midtide } \\
\text { levels }\end{array}$ & $3.96-13.20$ & \pm 0.02 \\
\hline
\end{tabular}

Stations G-Z are shown in Figure $1 ;$ msl, mean sea level.
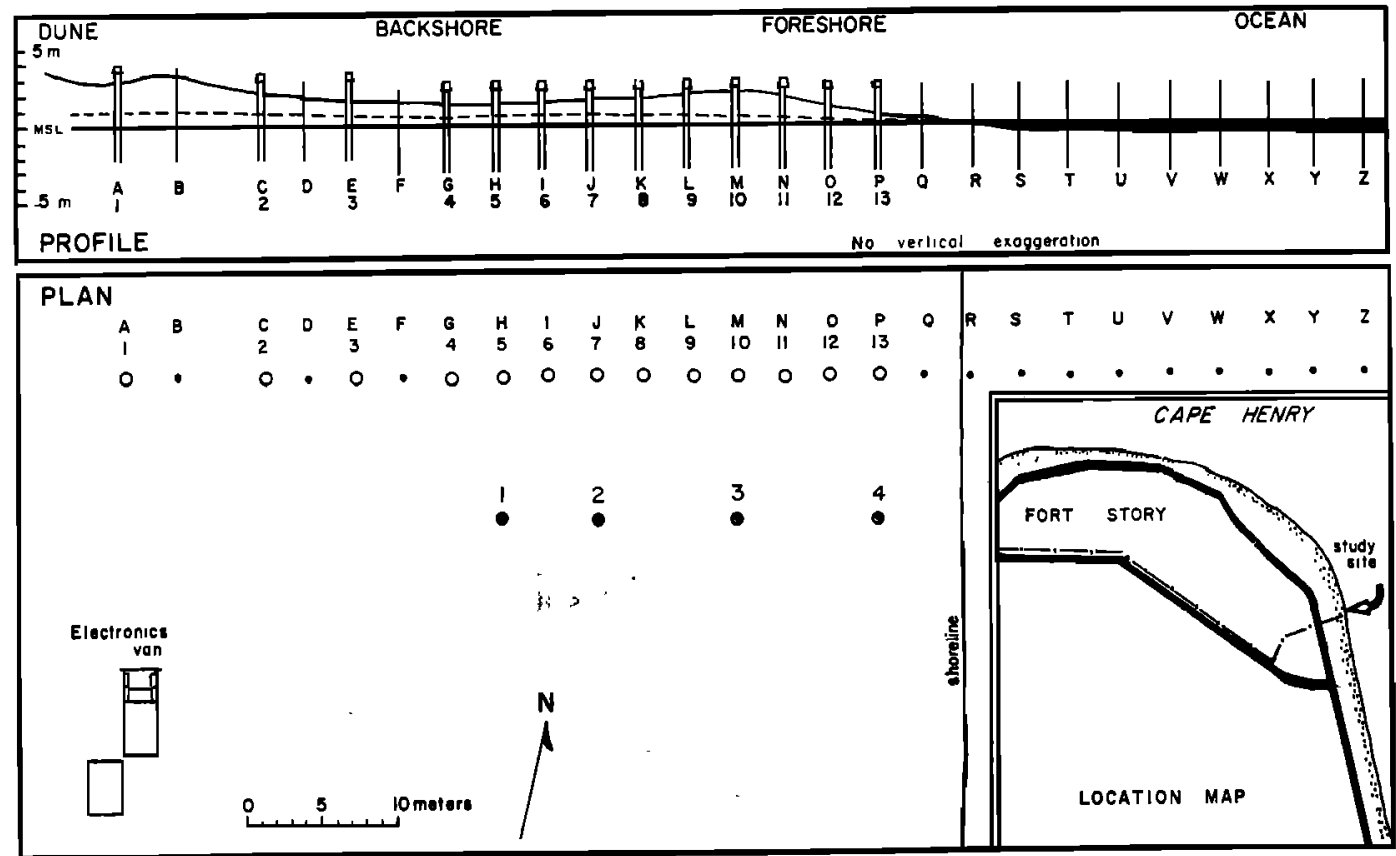

Fig. 1. Plan and profile views of the Fort Story study site (inset), showing typical beach and water table profiles, the spatial distribution of profile stations (A-Z), water table monitoring wells (1-13) and water table sampling probes (1-4). 
full tidal cycles. (Nine days were required for the groundwater level to return to its prestorm position.) In the remaining 17 days of the study, the wave climate was similar to that of the first 10 days. Rainfall amounted to $10.2 \mathrm{~cm}$ during the 30-day period. The greatest hourly rainfall was $2.22 \mathrm{~cm}$, an event that caused an increase of about $1.5 \mathrm{~cm}$ in the water level at all wells. The effects of rainfall, as well as sudden fluctuations in atmospheric pressure, can be ignored in the following.

\section{WATER TABLE RESPONSE CHARACTERISTICS}

It is commonly assumed [Chow, 1964, pp. 13-37] that for an unconfined aquifer connecting with the ocean, the tide wave will damp exponentially as it is propagated inland, so that, if the water table fluctuations are small relative to the saturated thickness, the amplitude $y$ at any distance $x$ inland is

$$
\begin{aligned}
y=h_{0} e \exp \left[-x\left(\pi S / t_{0} T\right)^{1 / 2}\right] \\
\cdot \sin \left[\frac{2 \pi t}{t_{0}}-x\left(\frac{\pi S}{t_{0} T}\right)^{1 / 2}\right]
\end{aligned}
$$

where $y=h_{0} \sin \omega t$ at $x=0$, and $y=0$ at $x=\infty ; t_{0}$ is the tide period, $T$ is the coefficient of transmissibility, $t$ is time, and $S$ is the storage coefficient. A seaward-directed head gradient is almost invariably present in beach aquifers, however. During rising tide, the head gradient causes the water table to rise more rapidly than predicted by equation 1 . During falling tide, the water table falls more slowly than predicted. Therefore, equation 1 cannot be used to model the tide wave response of the water table in a natural beach.

To gain insight into the response characteristics of the beach water table, Fausak [1970] performed the following linear multiregression analysis on the water table elevation data for each well:

$$
2 y=f\left(2 h_{0}, d, x, p\right)
$$

where $+2 y$ is the total change in elevation of the water table for a rising half tidal eycle, $+2 h_{0}$ is the total increase in elevation of the tide plane in a well for a rising half tidal cycle, $x$ is the horizontal distance from a given well to a point on the foreshore one-half the vertical distance between the preceding low water and the succeeding high water levels, $d$ is the verti- cal distance between the high tide still water level and a horizontal line passing through the average position of the swash at its highest level, and $p$ is the change in atmospheric pressure over a rising half tidal cycle (Figure 2 ).

The results of the regression analysis (Figure 3 ) indicate the significance of the tidal forcing function through most of the 50-meter width of instrumented beach. As expected, the distance of a well from the foreshore $x$ is the most signifcant factor in water table fluctuations for wells closest to the ocean. The regression analysis suggests that positive water table fluctuations in wells 12 and 13 (closest to the shore) will be as strong a function of $x$ as of the rise in the tide $2 h_{0}$. At the landwardmost well (Figure 3, well 1) the increase in water level is as much a function of $p$ as of $2 h_{0}$. In general, however, Figure 3 indicates that we may feel confident in using the tidal fluctuation as the primary forcing function when we are attempting to model water table fluctuations between wells 1 and 13. A certain amount of noise (unexplained variability) will be present in the output of any model, especially for the seawardmost end of the water table, owing to the unaccounted effects of the swash and the variable distance of the wells from the foreshore surface as sand is eroded and deposited.

Owing to the lack of information on porosity and hydraulic conductivity throughout the beach, only a small finite region was chosen for analysis. Also, owing to unmeasured factors at the bottom boundary, the finite difference approximation of boundary conditions for such a small region results in an unstable problem. Furthermore, the finite difference method seems to be restricted to a homogeneous isotropic medium or to an anisotropic medium with the two principle axes parallel in all parts of the flow region. The finite element method, however, requires no such restriction [Neuman and Witherspoon, 1970a]. Hence the finite element method was chosen for application and the field data were corrected by imposing a boundary condition referred to as the 'drainage velocity.'

Zienleiewicz and Cheung [1967] furnish considerable background, application, and research material on the finite element method. This method was introduced for analysis of fluid motion in porous media by Taylor and Brown [1967], Finn [1967], and Zienkiewicz et al, 


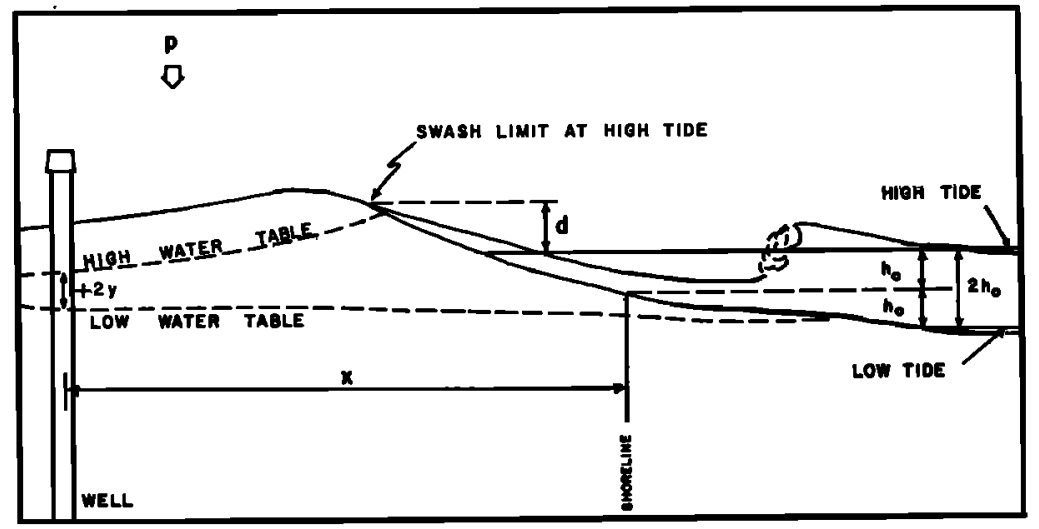

Fig. 2. Definition sketch for variables $y, x, d, h_{0}$, and $p$ used in the regression analysis.

[1966]. Recently Neuman and Witherspoon [1970b] have derived the general variational principle for transient groundwater flow. Guymon [1970] has applied finite element methods to solve the one-dimensional unsteady diffusionconvection problem.

\section{GROUNDWATER FLOW EQDATION}

A differential equation of groundwater movement was derived in accordance with the following assumptions: (1) that the flow is onedimensional, (2) that the density of the fluid is constant, (3) that Darcy's law is valid, (4) that the groundwater occurs in a homogeneous sand body, and (5) that the beach sand drains instantaneously.
According to the principle of conservation of mass, the continuity equation of groundwater in a homogeneous sand body can be written as

$$
-\frac{\partial}{\partial x}\left(K h \frac{\partial h}{\partial x}\right)+f \frac{\partial h}{\partial t}-V=0
$$

where $V=V(x, t)$ is a function describing the bottom mass flux of the groundwater, and

$$
\begin{aligned}
& x, \text { direction normal to the shoreline; } \\
& f, \text { porosity; } \\
& t, \text { time; } \\
& K \text {, hydraulic conductivity; } \\
& h \text {, total head. }
\end{aligned}
$$

When the variation principle is applied to (3) for conditions at a particular instant, the func-

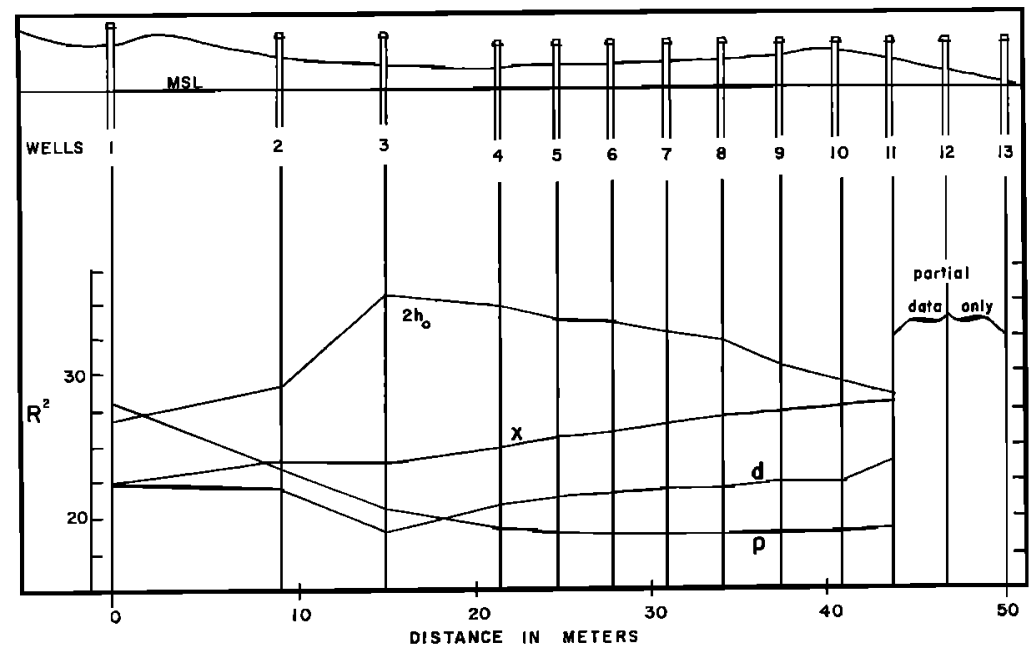

Fig. 3. Relative importance of $2 h_{0}, x, d$, and $p$, as indicated by percent reduction in sums of squares $\left(R^{2}\right)$ of $2 y$ [after Fausak, 1970, Figure 8]. 
tional of the minimizing function of $h$ for each element is:

$I^{m}=\int_{x_{n}}^{x_{n+1}}\left[\frac{1}{2} K h\left(\frac{\partial h}{\partial x}\right)^{2}+\left(f \frac{\partial h}{\partial t}-V\right) h\right] d x$

for all inner elements, and

$$
\begin{aligned}
I^{1} & =\int_{x_{1}}^{x_{*}}\left[\frac{1}{2} K h\left(\frac{\partial h}{\partial x}\right)^{2}\right. \\
& \left.+\left(f \frac{\partial h}{\partial t}-V\right) h\right] d x+\left[K h\left(\frac{\partial h}{\partial x}\right) \delta h\right]_{x=0}
\end{aligned}
$$

and

$$
\begin{aligned}
I^{M} & =\int_{x_{N}}^{x_{N+1}}\left[\frac{1}{2} K h\left(\frac{\partial h}{\partial x}\right)^{2}\right. \\
& \left.+\left(f \frac{\partial h}{\partial t}-V\right) h\right] d x-\left[K h\left(\frac{\partial h}{\partial x}\right) \delta h\right]_{x=L}
\end{aligned}
$$

for boundary elements.

It was assumed in deriving the preceding equations that $K h$ in the term $(\partial / \partial x)[K h$ $(\partial h / \partial x)]$ of $(3)$ was taken as the function of $x$ only [Volker, 1969]; also, $[f(\partial h / \partial t)-V]$ is treated as a function of $x$ at a particular time. Thus the variational principle can be applied directly to (3) [Weinstock, 1952].

The boundary was applied to the prescribed value of $h$ for each time step in this study; therefore (5) and (6) are identical to (4).

The general concept of the method is to imagine the surface subdivided into a group of subassemblages or elements that are interconnected only at the element joints. Thus the one-dimensional region is divided into many subregions (Figure 4).

If it is assumed that the linear function of $h$ passes through two end points of each element and if (4) is represented in local element coordinates, the contribution over the $m$ th element for the $(n-1)$ th node is given by:

$$
\begin{gathered}
\frac{\partial I^{m}}{\partial h_{n-1}}=\frac{3 k^{m}}{4 y^{m}} h_{n-1}^{2}-\frac{k^{m}}{2 y^{m}} h_{n-1} h_{n}-\frac{k^{m}}{4 y^{m}} h_{n}^{2} \\
+\frac{f^{m} y^{m}}{3} \frac{\partial h_{n-1}}{\partial t}+\frac{f^{m} y^{m}}{6} \frac{\partial h_{n}}{\partial t}-\frac{V^{m} y^{m}}{2}
\end{gathered}
$$

Similarly, for the $n$th node,

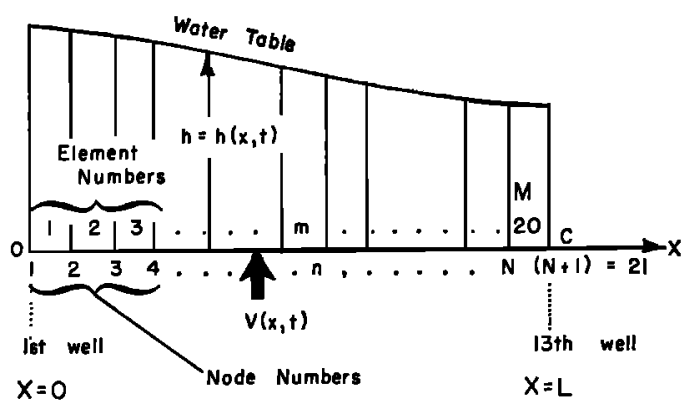

Fig. 4. Definition sketch for application of finite element model to field data.

$$
\begin{gathered}
\frac{\partial I^{m}}{\partial h_{n}}=-\frac{k^{m}}{4 y^{m}} h_{n-1}{ }^{2}-\frac{k^{m}}{2 y^{m}} h_{n-1} h_{n}+\frac{3 k^{m}}{4 y^{m}} h_{n}^{2} \\
+\frac{f^{m} y^{m}}{6} \frac{\partial h_{n-1}}{\partial t}+\frac{f^{m} y^{m}}{3} \frac{\partial h_{n}}{\partial t}-\frac{V^{m} y^{m}}{2}
\end{gathered}
$$

where $y^{m}$ is the length of the $m$ th element, the subscripts indicate nodal counters, and the superscripts indicate element counters.

Considering the overall contribution of derivatives of the minimizing function on nodal point $n$ due to all elements and setting equal to zero, one obtains:

$$
\frac{\partial I}{\partial h_{n}}=\frac{\partial\left(\sum_{m-1}^{M} I^{m}\right)}{\partial h_{n}}=\sum_{m=1}^{M} \frac{\partial I^{m}}{\partial h_{n}}=0
$$

That is,

$$
\left(\partial I^{m+1} / \partial h_{n}\right)+\left(\partial I^{m} / \partial h_{n}\right)=0
$$

Substituting (8) into (9) and expressing the results in matrix form yield:

$$
\begin{gathered}
{\left[-\frac{k^{m}}{4 y^{m}}\left(\frac{3 k^{m}}{4 y^{m}}+\frac{3 k^{m+1}}{4 y^{m+1}}\right)-\frac{k^{m+1}}{4 y^{m+1}}\right]\left[\begin{array}{l}
h_{n-1}{ }^{2} \\
h_{n}{ }^{2} \\
h_{n+1}{ }^{2}
\end{array}\right]} \\
+\left(-\frac{k^{m}}{2 y^{m}}-\frac{k^{m+1}}{2 y^{m+1}}\right)\left[\begin{array}{cc}
h_{n-1} & h_{n} \\
h_{n} & h_{n+1}
\end{array}\right] \\
+\left[\frac{f^{m} y^{m}}{6}\left(\frac{f^{m} y^{m}}{3}+\frac{f^{m+1} y^{m+1}}{3}\right)\right. \\
\left.. \frac{f^{m+1} y^{m+1}}{6}\right]\left[\begin{array}{l}
\partial h_{n-1} / \partial t \\
\partial h_{n} / \partial t \\
\partial h_{n+1} / \partial t
\end{array}\right] \\
+\left(-V^{m} y^{m} / 2-V^{m+1} y^{m+1} / 2\right)=0
\end{gathered}
$$


Equation 10 represents a system of nonlinear functions of $h_{n-1}, h_{n}$, and $h_{n+1}$ for every node.

For easy handling, (10) is defined as:

$$
\begin{array}{r}
f_{n}=\left(h_{2}, h_{3}, \cdots, h_{n-1}, h_{n},\right. \\
\left.h_{n+1}, \cdots, h_{N}\right)=0 \\
n=2,3,4, \cdots, N
\end{array}
$$

but

$$
n \neq 1 \quad n \neq N+1
$$

Thus

$$
\begin{aligned}
f_{n}= & A_{1} h_{n-1}{ }^{2}+A_{2} h_{n}{ }^{2}+A_{3} h_{n+1}{ }^{2}+A_{4} h_{n-1} h^{n} \\
& +A_{5} h_{n} h_{n+1}+A_{6} h_{n-1} \\
& +A_{7} h_{n}+A_{8} h_{n+1}+A_{9}=0
\end{aligned}
$$

When (10) and (12) are related, the coefficients $A$ are:

$$
\begin{aligned}
& A_{1}=-k^{m} / 4 y^{m} \\
& A_{2}= \frac{3 k^{m}}{4 y^{m}}+\frac{3 k^{m+1}}{4 y^{m+1}} \\
& A_{3}=-k^{m+1} / 4 y^{m+1} \\
& A_{4}=-k^{m} / 2 y^{m} \\
& A_{5}=-k^{m+1} / 2 y^{m+1} \\
& A_{6}= f^{m} y^{m} / 6 \Delta t \\
& A_{7}=\left(\frac{f^{m} y^{m}}{3}+\frac{f^{m+1} y^{m+1}}{3}\right) \frac{1}{\Delta t} \\
& A_{8}= f^{m+1} y^{m+1} / 6 \Delta t \\
& A_{9}=\left(-\frac{V^{m} y^{m}}{2}-\frac{V^{m+1} y^{m+1}}{2}\right) \\
&-\frac{f^{m} y^{m}}{6 \Delta t} h_{n-1}{ }^{t-\Delta t} \\
&-\left(\frac{f^{m} y^{m}}{3}+\frac{f^{m+1} y^{m+1}}{3}\right) \\
& \cdot \frac{h_{n}^{t-\Delta t}}{\Delta t}-\frac{f^{m+1} y^{m+1}}{6 \Delta t} h_{n+1}{ }^{t-\Delta t} \\
& \text { NOMERICAL ANALYSIS }
\end{aligned}
$$

\section{NOMERICAL ANALYSIS}

Basic steps. The basic steps in the formulation of the finite element method can be summarized as follows: (1) development of the element equation coefficient matrix, (2) genera- tion of the matrix for the entire system, (3) calculation of nodal head values due to imposed forces and boundary conditions, and (4) calculation of the water table elevation in each element from the nodal displacement.

There are three general methods for solving a system of nonlinear equations: (1) the Newton-Raphson method, (2) the secant method, and (3) the descent method. The choice of method depends on many factors, including the nature of the available data and personal preference, but the most important points are efficiency and accuracy. Of the well-known methods for solving a general set of simultaneous, nonlinear equations in which the corrections are computed as linear combinations of the residues, the generalized Newton-Raphson iterative method is considered the best and
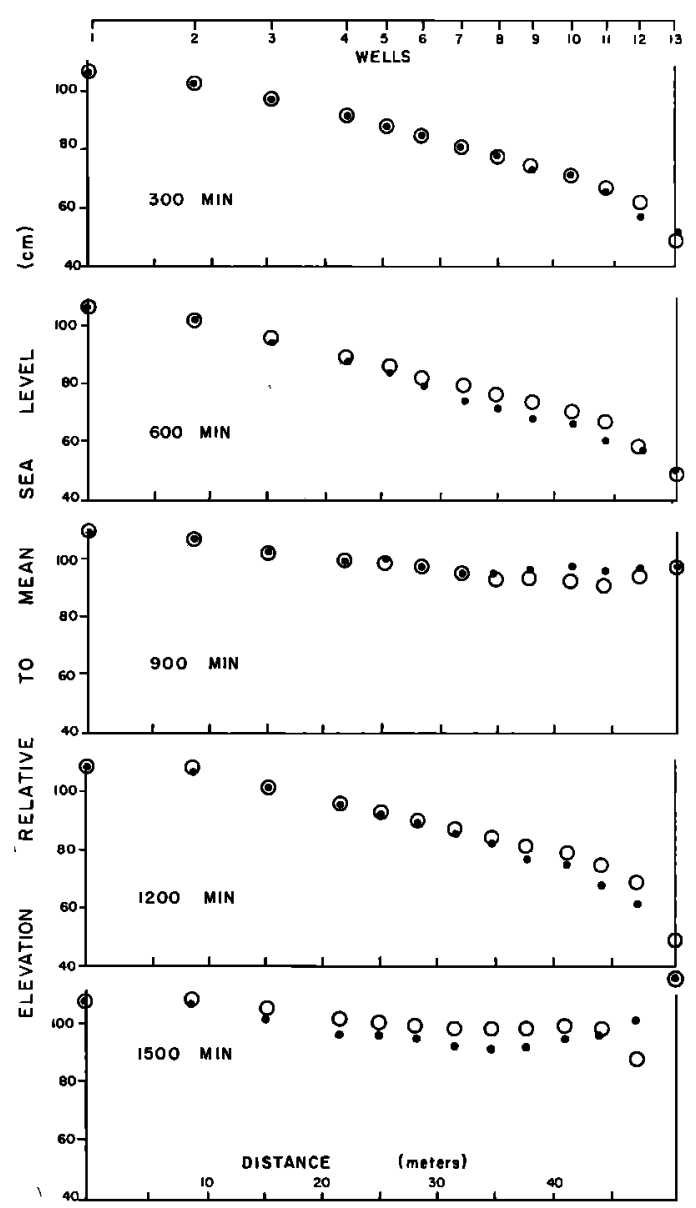

Fig. 5. Comparison between field data (solid circles) and computer results (open circles). 
was used here to solve (10). Fang [1968] has given a detailed description of this method. A brief discussion follows.

Denote the $k$ th approximation of iteration for the actual roots $\left[h_{i}\right], i=1,2, \cdots, I$, as $\left[h^{(k)}\right]$; then (11) may be expanded in Taylor series about $\left[h_{i}{ }^{(k)}\right]$, higher order other than first derivative terms being truncated:

$$
\begin{aligned}
& F_{i}\left[h_{i}{ }^{(k+1)}\right]=F_{i}\left[h_{i}{ }^{(k)}\right] \\
& \quad+\sum_{i=1}^{I} \frac{\partial F_{i}\left[h_{i}{ }^{(k)}\right]}{\partial h_{i}}\left[h_{i}{ }^{(k+1)}-h_{i}{ }^{(k)}\right]
\end{aligned}
$$

If $h_{i}{ }^{(k+1)}$ are found close to the actual root, then $F_{i}\left[h_{\mathfrak{i}}^{\left({ }^{(k+1)}\right]}\right]=0$. Equation 13 represents a system of linear equations that can be expressed in matrix form as

$[J]\left[h_{j}{ }^{(k+1)}-h_{j}{ }^{(k)}\right]=-\left\{F_{i}\left[h_{i}{ }^{(k)}\right]\right\}$

where $[J]$ is the Jacobian matrix.

The Jacobian matrix has the form

$$
[J]=\left[\begin{array}{llll}
\frac{\partial F_{1}}{\partial h_{1}} & \frac{\partial F_{1}}{\partial h_{2}} & & \\
\frac{\partial F_{2}}{\partial h_{1}} & \frac{\partial F_{2}}{\partial h_{2}} & \frac{\partial F_{2}}{\partial h_{3}} & \\
& \frac{\partial F_{3}}{\partial h_{2}} & \frac{\partial F_{3}}{\partial h_{3}} & \frac{\partial F_{3}}{\partial h_{4}} \\
& & & \cdots \\
0 & & & \\
& & & \\
& & &
\end{array}\right.
$$

Note that each row of the Jacobian matrix contains at most three nonzero elements. For large $I$ the matrix is spare and one can take advantage of the large number of zeros. The modified subroutine from the IBM system 360 subroutine package (SIMQ) takes advantage of the large number of zeros in the matrix of coefficients by using the Gaussian elimination method, which gives a rapidly convergent procedure with the generalized Newton-Raphson iteration method.

That is, all the nonzero elements of $[J]$ are placed on the diagonal region. There are only three nonzero elements for each row, except for the first and final rows, in which there are two nonzero elements.

The iterative steps may be summarized as follows:

1. Find $\left[h_{t}{ }^{(k)}\right]$. (It must be a close approximation to the root; otherwise the equation may not converge.) For the first iteration the value of the previous time step is used as an approximation; if $k>0$, the result of the previous iteration is used.

2. Compute

$$
\Delta h_{i}=h_{i}{ }^{(k+1)}-h_{i}{ }^{(k)}
$$

by solving the system of linear equations (equation 14).

3. Find $h_{f}^{\left({ }^{(k+1)}\right.}$ by using a reasonable convergent criterion.

Boundary conditions. The prescribed values

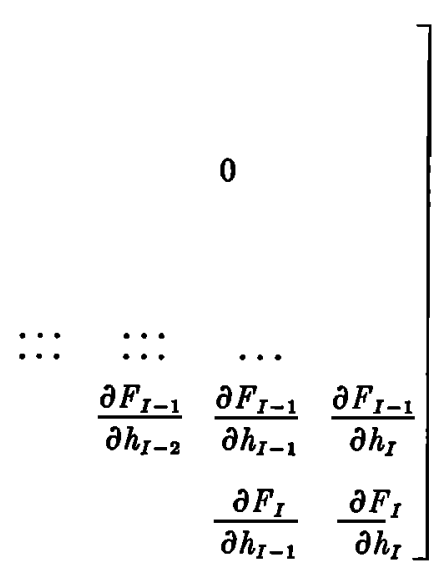

of $h$ obtained from the field experimental data are applied to the left- and right-hand boundary nodal points.

The most confused boundary condition occurs on the bottom side of the control region. As mentioned in the last part of. the section on water table response, the lateral and bottom fluxes were lumped into drainage velocity as sinks or sources that affect the beach groundwater flow severely. It is difficult to handle the drainage velocity function $V(x, t)$ in proper mathematical form because this boundary is a function of both space and time, owing to 


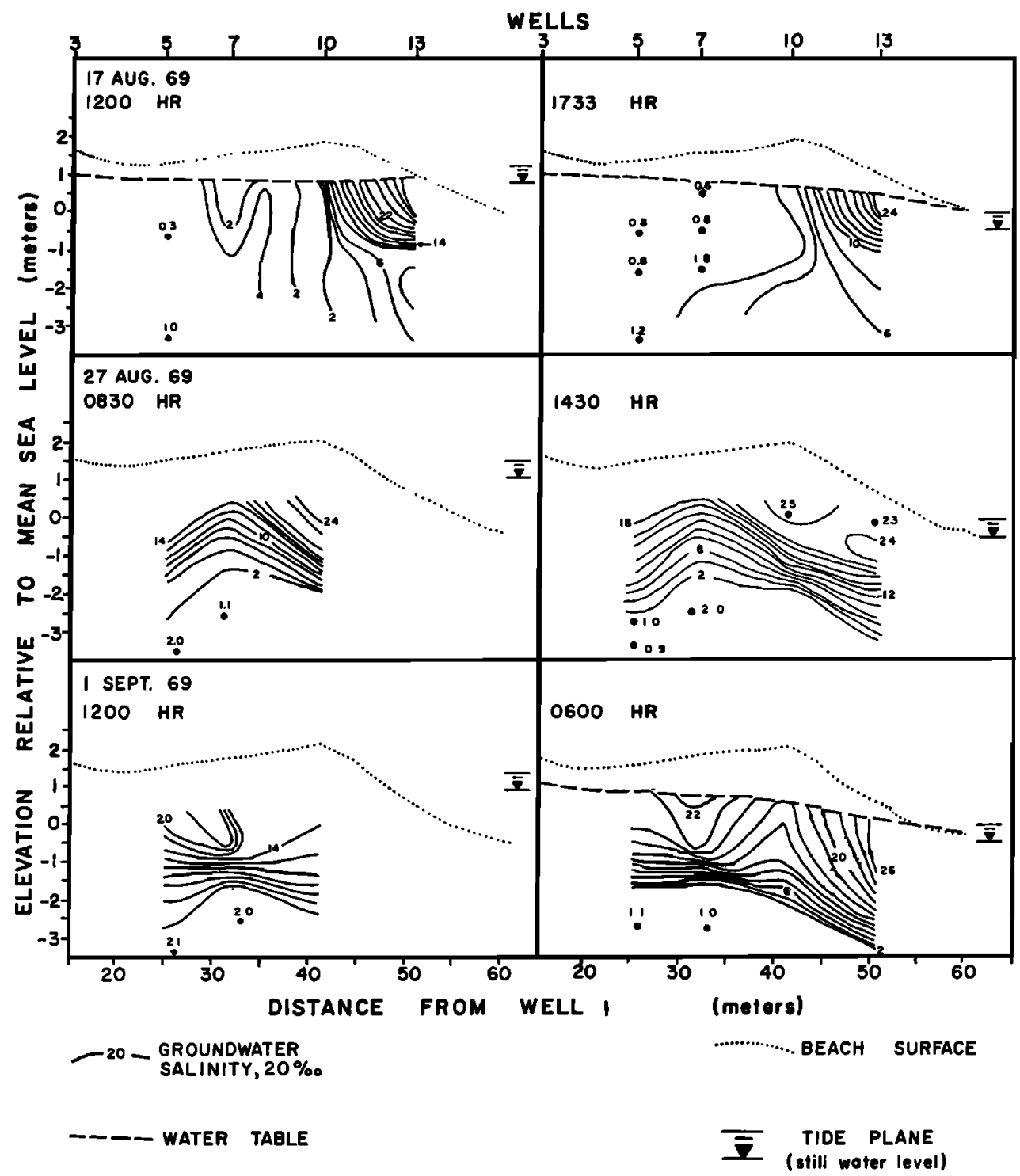

Fig. 6. Salinity structure of the beach groundwater before (August 17, 1969) and after (August 27, 1969) storm wave flooding of backshore.

the combined effects of the tide, waves, foreshore changes, and rainfall.

Fourier series analysis for drainage velocity. Assume that $V(x, t)$ is constant over each interval $x_{t} \leq x \leq x_{t+1}$ and can be calculated from actual field data by the Eulerian finite difference formulation, where $i=1,2, \cdots, 12$, and the $x_{i}$ are the coordinates of the wells.

From the results of the Eulerian finite dif.. ference method, we find that $V(x, t), x_{i} \leq x \leq$ $x_{i+1}$, shows much fluctuation from time to time. To simplify the Fourier series analysis, we first take the time average:

$$
\begin{aligned}
& \langle V\rangle(x, t)=\frac{\sum_{n=1}^{N} V\left(x, t_{n}\right)}{N} \\
& x_{i} \leq x \leq x_{i+1} \quad t_{1} \leq t \leq t_{n}
\end{aligned}
$$


In our example we take 100 time cycles (each cycle is $\mathbf{1 5}$ minutes) as the period. If the time average is taken for each 20 cycles, three average values in each average interval give a more accurate Fourier series.

The average value of two different intervals is taken as the value at the point of discontinuity. We then find the Fourier series:

$$
\langle V\rangle(x, t)=\sum_{n=1}^{N}\left(a_{n} \cos \frac{2 \pi n t}{T}+b_{n} \sin \frac{2 \pi n t}{T}\right)
$$

for each well interval. The Fourier series coefficients are used in the subroutine to find the drainage velocity for each time step.

\section{APPLICATION OF THE METHOD}

The analytical method was applied to the field data as follows (Figure 4): The prescribed values of $h$ were applied at $C$ and 0 for every time step. The drainage velocity $V(x, t)$ was applied on the bottom boundary $\langle 0 C\rangle$ as the source term. Also, the following data were used in the example: 21 total nodes; $34 \%$ porosity; hydraulic conductivity, $0.014 \mathrm{~cm} / \mathrm{sec}$; length of each element, $250 \mathrm{~cm}$; time increment for each step, 15 minutes.

\section{RESULTS AND CONCLUSION}

The finite element method was applied to solve the nonlinear equation for treating the complicated case of beach water table fluctuations. The finite element method, based on the variational principle, provides an accurate solution with an economy of computer time. A compromise decision was made as to the assumed position of the boundaries. In the finite element analysis, the semi-infinite mass (unconfined aquifer) was replaced by a finite mass. The drainage velocities were found from the field data by calculating the pertinent differential equation directly with a finite difference technique. Then a Fourier function was used to describe the mean regional drainage velocity characteristics and the beach water table response to the input tidal fluctuation. Comparing the results (Figure 5) of this procedure and the field data indicates that the finite element method is accurate enough to solve the problem of fluctuation of the beach groundwater table.
The small differences between the field data and the theoretical results are due to the effects of $x$ and $d$ (equation 2) mentioned earlier. The effects of capillarity and groundwater density gradients are also important (these effects possess a complex relationship to space and time). Density gradients in the groundwater are due to variations in water temperature and salinity [cf. Jansson, 1967]. As shown in Figure 6 , the groundwater salinity for the summer beach (August 17, 1969) ranged from near zero at well 3 to $26 \%$ (parts per thousand) at well 13 at high tide (1200 hours). At low tide (1733 hours) the saline groundwater had migrated slightly seaward. At the end of a storm that sent ocean water over the berm and onto the backshore, however, the salinity of the groundwater had increased markedly (Figure 6). (Flushing of the saline water can be gaged by the distance moved by the $18 \%$ isoline (about 8 meters) in the 87.5 hours between 1430 on August 27 and 0600 on September 1.) The point is that a normal horizontal density gradient in the beach groundwater changed to a vertical density gradient as the result of storm flooding.

The procedure developed in this study can be applied to noneven elements and nonhomogeneous materials and makes it possible to predict water table fluctuations in any sandy, two-dimensional tidal beach, when only the drainage velocity (obtained from two wells) and the predicted fluctuations in ocean level are known.

The existence of small oscillations in computer results near the ocean boundary indicates that the hydrostatic assumption is critical in this region, in which the effects of tidal forces and seaward-directed head gradient are important. Apparently the idea of imposing a drainage velocity to improve the one-dimensional model has not completely solved the problem. Subsequent work will be concerned with the two-dimensional case and will use triangular elements to improve this deficiency.

Acknowledgments. This research was supported by the Geography Branch of the Office of Naval Research under contract Nonr-N0001470-C-000A (ONR task NR 388-097). We thank Drs. John Bredehoeft and George Pinder for critical review of the manuscript. Contribution 392 of the Virginia Institute of Marine Science. 


\section{REFERENCES}

Chow, V. T., Handbook of Applied Hydrology, 704 pp., McGraw-Hill, New York, 1964.

Duncan, J. R:, The effects of water table and tide cycle on swash-backwash sediment distribution and beach profile development, Mar. Geol., 2(1), 186-197, 1964.

Emery, K. O., and J. F. Foster, Water tables in marine beaches, J. Mar. Res., 7(3), 644-654, 1948.

Fang, C. S., Mathematical solution of the complete equations of unsteady flow in open channels, Ph.D. thesis, N. C. State Univ., Raleigh, 1968.

Fausak, L. E., The beach water table as a response variable of the beach-ocean-atmosphere system, M.S. thesis, 51 pp., Univ. of Va., Charlottesville, 1970.

Finn, W. D., Finite element analysis of seepage through dams, J. Soil Mech. Found. Div., Amer. Soc. Civil Eng., 98(6), 41-48, 1967.

Grant, U. S., Influence of the water table on beach aggradation and degradation, J. Mar. Res., 7 (3), 655-660, 1948 .

Guymon, G. L., A finite element solution of the one-dimensional diffusion-convection equation, Water Resour. Res., 6(1), 204-210, 1970.

Harrison, W.. and L. E. Fausak, A time series from the beach environment, 2, Data Rep. 7, pp. 1-96, Va. Inst. of Mar. Sci., Gloucester Point, 1970.
Jansson, B.-O., Diurnal and annual variations of temperature and salinity of interstitial water in sandy beaches, Ophelia, 4, 173-201, 1967.

Neuman, S. P., and P. A. Witherspoon, Finite element method of analyzing steady seepage with a free surface, Water Resour. Res., 6(3), 889-897, 1970a.

Neuman, S. P., and P. A. Witherspoon, Variational principles for confined and unconfined flow of groundwater, Water Resour. Res., 6(5), 1376-1382, $1970 b$.

Taylor, R. L., and C. S. Brown, Darcy flow solutions with a free surface, J. Hydraul. Div., Amer. Soc. Civil Eng., 93(2), 25-33, 1967.

Volker, R. E., Nonlinear flow in porous media by finite elements, J. Hydraul. Div., Amer. Soc. Civil Eng., 94(6), 2093-2114, 1969.

Weinstock, R., Calculus of Variations with Application to Physics and Engineering, 328 pp., McGraw-Hill, New York, 1952.

Zienkiewicz, O., and Y. K. Cheung, The Finite Element Method in Structure and Continuum Mechanics, 406 pp., McGraw-Hill, New York, 1967.

Zienkiewicz, O., P. Mayer, and Y. K. Cheung, Solution of anisotropic seepage by finite elements, J. Eng. Mech. Div., Amer. Soc. Civil Eng., 9\&(1), 111-120, 1966.

(Manuscript received April 15, 1971; revised May 21, 1971.) 